\title{
Social Determinants of Intention to Dope in Sports Clubs and Institutions
}

\section{Delia Nica-Badea}

Faculty of Medicinal and Behavioral Sciences, Department of Sport and Health, Constantin Brancusi University, Târgu-Jiu, Romania.

\begin{abstract}
Doping is the use of drug for the purpose of improving performance in general and sports performance in particular. Rejection or acceptance of the use of banned substances by athletes is determined by internal factors that are subjective and external or social. Against this background, the present study examined social risk factors as determinants of intention (temptation) to use banned substances and explored the willingness of athletes at the national level, to report the use of substances that enhance performance. The survey method was a self-report questionnaire based on the Romanian National Anti-Doping Agency (NADA) model of approaching risk factors associated with the use of prohibited substances, collection of demographic data and use of the Performance Enhancement Attitude Scale (PEAS). The subjects were 171 athletes (mean age $=19.75$, std. error $=0.103$ ) and 30 coaches in sporting institutions and universities. The results reveal a complex distribution of environment-specific social-proximity influences of athletes, including the family, social class or professional institution, leisure group, sports team, sports clubs and social representation. The rate of prevalence for performance-enhancing drugs (PED) was $1.23 \%$ to $12.0 \%$ for NADA ( $<<0.05$ ) and $1.1 \%$ to $15.0 \%$ for the PEAS ( $\mathrm{p}<0.001$ ) and fall into ranges reported by recent studies $(1.2 \%$ to $25.8 \%)$. The approach used took into account the assumption that doping is a rational behavior and intentional. As such, it provides points of intervention that influence decision-making. The findings reveal the need to consider the contribution of several social support factors that contribute to the trend abuse drugs that increase performance.
\end{abstract}

KEY WORDS: Social-Environmental Factors, Performance Enhancing Drug, Doping Intention.

\section{INTRODUCTION}

Despite efforts by the World Anti-Doping Agency, International Olympics Committee and sports federations, worldwide doping by participants at various levels and in different sports $(1,2)$ has been proven to exist. In high performance sports, statistics on prevalence vary widely and include self-report studies citing $1.2 \%$ to $25.8 \%$ (3-9) use and from the randomized response technique (RRT) citing $6.6 \%$ (10) to $35 \%$ use (2). The sports clubs and institutions investigated were sports high schools, sports clubs in secondary and higher education, representative sporting institutions in three cities in Romania, universities with majors in physical education and competitive sports at the regional, national and international levels through the institutions they represent.

*. Corresponding Author:

Delia Nica-Badea

E-mail: nicabadeadelia@yahoo.com 
The focus of research was to identify the potential psychological and social variables linked to the use of PEDs (9-15). Research on social and psychological determinants of the use of prohibited substances in sport are based on the theory of planned behavior (TPB) and social cognitive theory (STC) that describe behavior by intention. Intention, in turn, depends on attitudes, social influences and self-efficacy (10, 16-20). Petróczi and Aidman (2008) classified factors influencing the behavior of doping on three structural levels: personality factors (increased performance, commitment, low self-esteem, anxiety), systematic factors (motivational climate, structure of authority) and situational factors (interaction of group members, role models, ambient factors) (21). Social influences are reflected in subjective norms, perceived social support and behavior (22).

The Romanian National Anti-Doping Agency (NADA) groups risk factors for doping as individual, social and situational (Table 1) (13). Based on these models and the hypothesis that the best predictor of behavior is intention, a selfreport study was proposed to analyze the phenomenon of doping in national sports clubs (23-25). The model (13) defines social risk factors as the attitude and behavior of rejecting or accepting the use of prohibited substances as determined by internal factors, which are subjective and external social-environmental factors, especially the entourage. The athlete is the product of his own development and socialeducational-cultural factors. These models provide complementary analysis of risk factors associated with the use of doping substances. Studies have shown specific ways of thinking and systematization of information. NADA is summarized in Table 1 and the steps are described in the Materials and Methods section.

Table 1. Romanian NADA model of approaching risk factors associated with use of prohibited substances

\begin{tabular}{lll}
\hline \multicolumn{1}{c}{ Individual } & \multicolumn{1}{c}{ Risk factors } \\
\hline 1. Personality traits & \multicolumn{1}{c}{ Social } & \multicolumn{1}{c}{ Situational } \\
2. Performance motivation; & or professional institution & 2. Rivals perceived as threats \\
victory no matter the cost. & 2. Leisure group: sports team, & 3. Factors of uncertainty in area of \\
3. Self-image. & sport club & competition \\
4. Specific attitudes & 3. Social environment: mass- & \\
5. Culture and education level & media, civil society, social \\
& $\begin{array}{l}\text { representation over sport and } \\
\text { athlete status }\end{array}$ \\
\hline
\end{tabular}

\section{MATERIALS AND METHODS}

Participants. The subjects were 171 athletes 14 to 30 years of age (mean age $=19.75 \pm 0.103$; median age: $19.00 ;$ variance $=14.786 ; \mathrm{SD}=$ 3.845 ; range $=16$ ). The target groups studied were sports high-schools, sports clubs in secondary and higher education and sports associations in the cities of Târgu-Jiu, ClujNapoca and Constanta (23), representative sporting institutions in those cities, universities with majors in physical education and competitive sports at the regional, national and international levels through the institutions they represent. During the study, planned activities included meetings with youth and students in schools and clubs, students in university sports, professional athletes, coaches, administrative and technical leadership in sporting associations. The participants were informed as regards the content and research methodology, thus obtaining the agreement of principle and confidentiality of the data collected in the study.

Tools. The survey method used to collect demographic data and opinions was the NADA self-report questionnaires for athletes and coaches $(13,26)$ and PEAS $(27,28)$. The NADA questionnaires for athletes and coaches was composed of 57 items on a subject's: a) knowledge about types of prohibited substances and their effects; b) knowledge of the sanctions that might be imposed if an athlete is caught using a prohibited substance; c) rejection or acceptance of the use of prohibited substances; d) reasons for which an athlete would assume the 
risk of using a prohibited substance; e) proximity to social environment (sport group, teammates) and mass-media factors that influence subject attitude towards doping; f) suggestions for athletes and their entourage about education to reject doping; g) self-references to prohibited substance use and its consequences. The validity and reliability were reported by the World AntiDoping Agency and a NADA report on a funded research project in 2007 (13).

Demographic data comprised nine questions that collected personal data, determined if the subject had ever inadvertently/knowingly taken a substance whose use is prohibited in their sport, knowledge about banned substances in their sport and personal knowledge of any athletes who are taking or have previously taken prohibited substances. The original PEA contains 17 items distributed on a six- level scale measuring attitude expressed towards achieving performance through drugs and prohibited methods that ranged from strongly disagree (1 point) to strongly agree (6 points). A high score denoted a positive or permissive attitude to doping. Cronbach's alpha for this scale is 0.85 . The scores ranged from 17 to 102 .

Statistical Analysis. All data was processed with SPSS software (version 10.0.7) allowing analysis of the factors influencing the intention of doping. Chi-square tests and Fisher's exact tests were used to assess differences in background characteristics between sportsmen.

This research was based on combined use of distinct qualitative and quantitative methodologies. The instruments were those of focus-groups, in-depth interviews, and completing a questionnaire. The necessity for interviews as well as questionnaires was demonstrated by the lack of clear data on prohibited substance use in Romania, which was necessary for gathering detailed information to develop user and riskexposed population profiles. The following was sought in the self-report questionnaire for athletes: attitudes, information, decisions and influence of entourage. It was presumed that the subjects had participated in the related sport, as these are reflected in the answers to the items $(13,14)$.

\section{RESULTS AND DISCUSSION}

Cultural and social-environmental factors. Of the 171 respondents, $133(78 \%)$ claim to know of the existence of a list of prohibited substances and methods and 7 remained tempted to use prohibited substances $(5.2 \%)$. The number of adults was significantly higher than youth (2 youth, 5 adults; $x=12.7 ; p=0.05$ ). For athletes who did not know about the list of permitted substances $(38 ; 22 \%)$, the number of those who remained tempted was $4(10.5 \%)$ and the difference between the number of youth and adults was not significant $(\mathrm{p}=0.05 ; \mathrm{x}=3.36)$. Although the number of athletes who knew they would be punished if they use prohibited substances and methods was 146 (90.4\%), the temptation to use them remained for 8 athletes (5.4\%), 3 youth and 5 adults, and the difference was significant $(\mathrm{p}=0.05 ; \mathrm{x}=12.23)$. The number of the athletes who did not know about the sanctions but remained tempted to use PEDs was $25(10.6 \%)$. Three of these athletes were tempted to use PEDs (12\%), the difference between youth and adults was not significant ( $\mathrm{p}$ $=0.05, \mathrm{x}=3.03$ ). It appears that the lack of a list of doping sanctions represents an additional risk for both age and level of performance.

For the $50.7 \%$ of the athletes who claim to have information about doping, the information was deemed very useful $(26.8 \%)$, useful $(12.6 \%)$, rather unnecessary $(6.9 \%)$, and useless $(5.6 \%)$. Data analysis shows that $87 \%$ of those who need information are those who are not tempted to use prohibited substances and $88 \%$ categorically reject the use as opposed to the athletes who consider that the information usefulness was very low (157 athletes), for which $12 \%$ say they would be tempted to use prohibited substances in the future or will use them in the future $(8.5 \%)$.

The behavior of rejecting or accepting the use of prohibited substances was determined by internal factors which are subjective and external factors, which are social-environmental. These latter particularly include the entourage (physician, coach, colleagues, friends, partners, parents and others). The weight and intensity of attitudes under the influence of proximity to the social environment is shown in Figure 1. The sources of tolerance and inciting doping in the entourage were: $6.2 \%$ said that the doctor would agree to use of prohibited substances and methods; $5.1 \%$ said the coach; $6.1 \%$ said teammates; $5.3 \%$ said teammate's friends; $3.1 \%$ 
said fathers, $4.5 \%$ said partner and $8.7 \%$ said friends.

Attitude towards use of prohibited substances. Of the 171 respondents:

- Temptation to use prohibited substances: 5.3\% athletes said they would be tempted to use banned substances in order to achieve their objectives, $82 \%$ that they were not tempted and $12.7 \%$ that they do not know. Eight athletes (3 youth and 5 adults) state they were or they could become users of prohibited substances.

- Acceptance of use by other athletes: $14.2 \%$ said they would agree to compete with those who dope, $77.2 \%$ said they would not compete and $8.6 \%$ did not take a position ( $\mathrm{n}$ $=134)$.

- Reject use of doping: $7.1 \%$ of those investigated know people suggesting the use of prohibited substances and $92.9 \%$ do not know such persons. Among the $82 \%$ of athletes opposed to the use of prohibited substances, only $6.9 \%$ were somewhat against, $5.6 \%$ had not decided, $2.3 \%$ were somewhat not against and $3.6 \%$ were not against.

- Moral objections: $94.1 \%$ of athletes said that those who dope should be sanctioned. Although the majority of athletes reveal a moral attitude towards the use of prohibited substances, 5 did not exclude the possibility of using a prohibited substance (2 youth and 3 adults). Although the difference was not statistically significant, it can be said that adults are the most tempted to use prohibited substances.

- Accepting the risk: $54.7 \%$ said the effect of doping equals the risk, $12.5 \%$ said it does not equal the risk, and $32.8 \%$ did not know. About $53.4 \%$ athletes would use substances that improve their performance if someone guaranteed they would not get caught.

Reasons for doping. Of the basic practical arguments that would influence the intention to use banned substances to enhance performance of athletes, $60.6 \%$ said the chance to gain materially ( $46 \%$ states they are tempted to use prohibited substances for a prevalence rate of $1.23 \%) ; 60.5 \%$ believed that the desire for fame; $34.4 \%$ said doubt or uncertainty $(78 \%$ were tempted for a prevalence rate of $2.3 \%$ ); $18.2 \%$ felt anxiety (mostly youth); $25 \%$ said lack of information and $53 \%$ to break performance records.

The opinions of coaches about the factors that encourage athletes to use prohibited substances included: the desire to achieve high performance in a short time (20\%), get results (16\%), affirmation (14\%), team influence (12\%), material gain, financial gain $(12 \%)$, family pressure (16\%), lack of information (5\%), lack of information about risk (2\%), other (4\%: muscular ability, fitness, afraid to compete, family problems, body building magazines scored less than $1 \%$ each). The educational factors responsible for anti-doping education to athletes emphasize that $23 \%$ rely on the coach/instructor, $22 \%$ on the medical community, $18 \%$ on school, $15 \%$ on family, $8 \%$ on NADA, $7 \%$ on media, federations and clubs.

Self-reported prevalence (DI-PEAS model). Evaluation of responses items for athletes who currently use or have used prohibited substances or methods were categorized according to level of perception, purpose and statistical characteristics (Table 2). A total of 17 athletes $(10 \%)$ were inadvertently doped in 4 cases (2.2\%) to improve performance, in 11 cases (6.4\%) through recreational use and in 2 cases $(1.1 \%)$ both reasons applied. A total of 18 athletes $(10.5 \%)$ responded "yes" to the question of having doping knowingly, of which $2(1.1 \%)$ did it to increase performance, $14(8.0 \%)$ for recreational purposes and $2(1.1 \%)$ for both reasons. Almost half of the group of athletes (72; $42 \%$ ) responded "yes" to the question about knowing of others who dope of which 27 (15\%) believed it was done to increase performance, 30 $(17 \%)$ for recreational use and $15(8.5 \%)$ for both. Of those who reported the intent to dope, the rate of doping was $62 \%$ (107), 4 reported having used prohibited substances inadvertently, 2 knowingly, and 72 who knew of others who dope. 
$\square$ Very much $\square$ Much enoug $\square$ Little $\quad$ Very little $\square$ Not at all

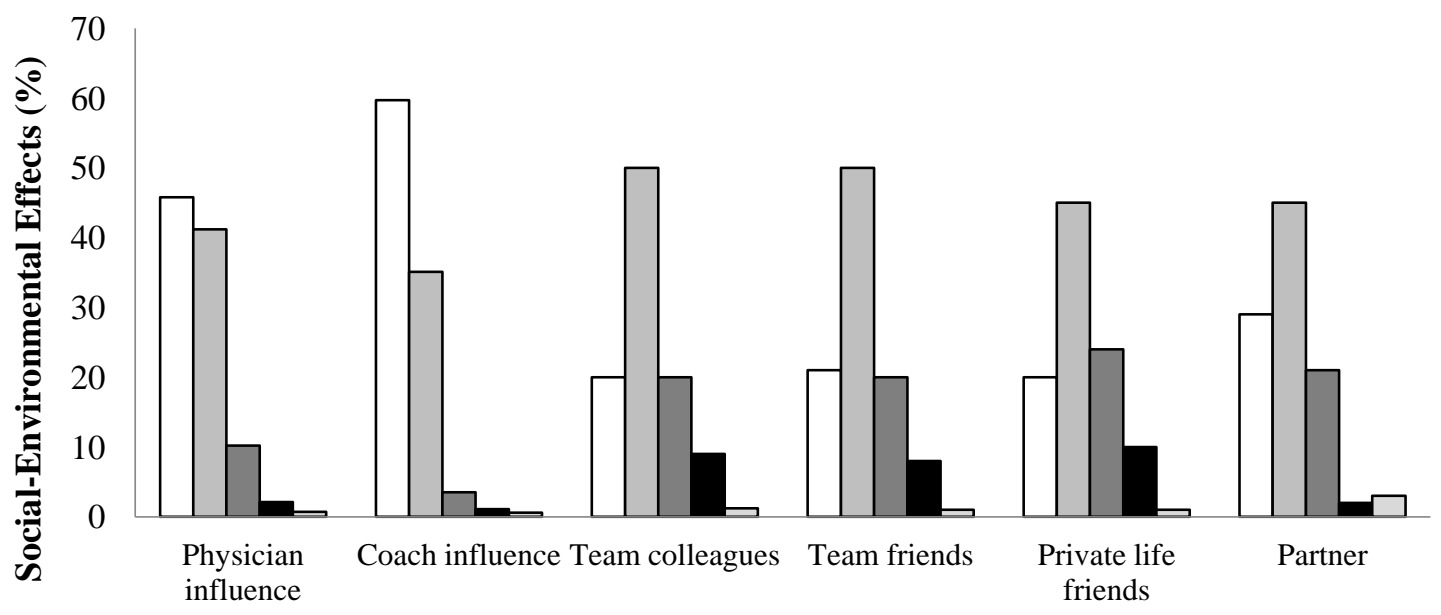

Figure 1. Level of social-environmental influence on intent to dope.

Table 2. Perception of doping by athletes.

\begin{tabular}{lccccccc}
\hline \multicolumn{1}{c}{ Doping perception } & \multicolumn{1}{c}{ Purpose of use } & \multicolumn{5}{c}{ Statistical variables } \\
t-tests \\
\hline \multicolumn{1}{c}{ Variable } & PE & R & Both & mean PEAS & p & t & df \\
\hline Inadvertently doped $(\mathrm{n}=17)$ & 4 & 11 & 2 & 39.20 & $.035^{*}$ & 2.29 & 36.93 \\
Knowingly doped $(\mathrm{n}=18)$ & 2 & 14 & 2 & 38.12 & $0.023^{*}$ & 2.25 & 43.20 \\
Knows others who dope $(\mathrm{n}=72)$ & 27 & 30 & 15 & 40.15 & $0.000^{* *}$ & 5.12 & 292.90 \\
\hline
\end{tabular}

$* \mathrm{p}<0.05 ; * * \mathrm{p}<0.001$

$\mathrm{PE}=$ performance enhancing; $\mathrm{R}=$ recreational

$\square$ Performance Enhancing $\quad$ Recreational $\quad$ Both

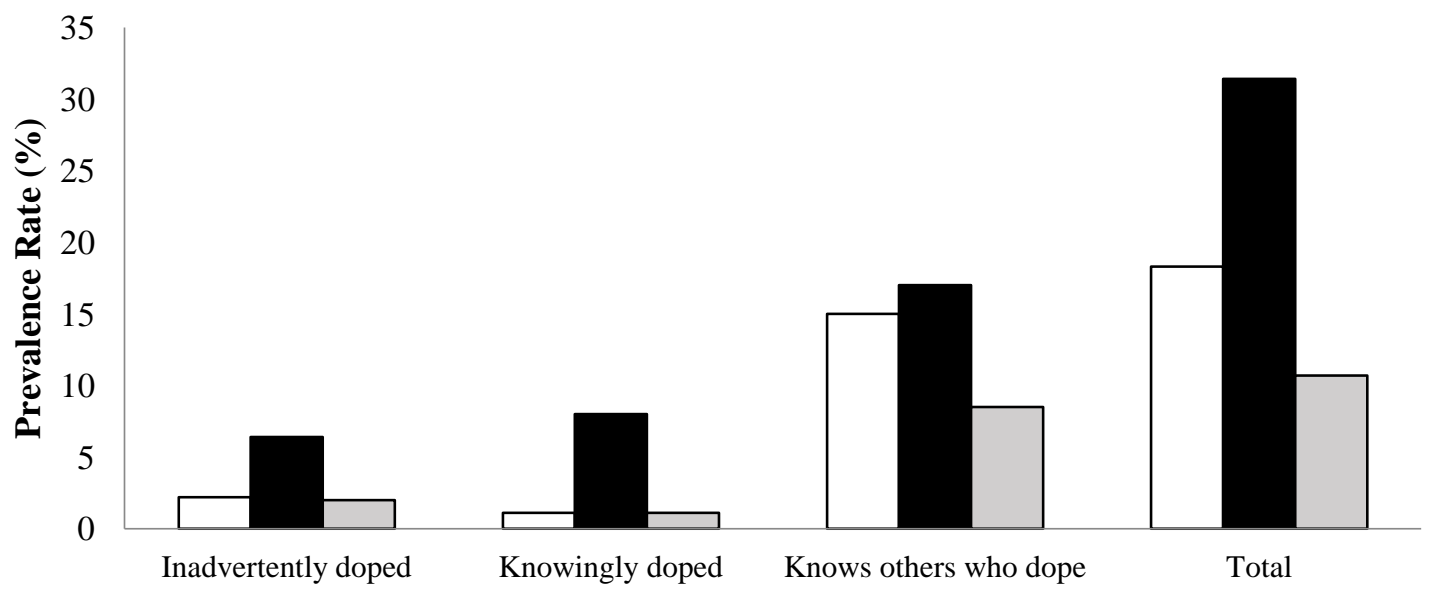

Figure 2. Variables of self-reported doping prevalence

Nica-Badea, D. (2016). Ann Appl Sport Sci, 4(2): 33-40. 
The prevalence of use of PEDs varied widely for the three responses $(1.1 \%-15 \%)$. The rates of use for recreational purposes $(6.4 \%-17.0 \%)$ or for other reasons $(1.1 \%-8.5 \%)$ were significantly higher (Figure 2). The rate of prevalence of doping in recent studies was similar to the results of this study. Several studies used self-report to obtain prevalence rates. Laure (1997) estimated that 3\%-5\% of children and teens and $5 \%-15 \%$ of adults had doped based on self-report. Özdemir et al. (2005) estimated that $8 \%-14.5 \%$ had doped in a crosssectional study based on a self-report questionnaire (29). Alaranta et al. (2006) reported a low of $30 \%$ (30). WADA Accredited Laboratories reported values between $1 \%-3 \%$ (8). Laure and Binsinger (2007) reported $1.2 \%-3.0 \%$ among preadolescent athletes (31). Similarly, the number of athletes who reported personally knowing athletes who doped (15\%) was compared the percentages reported in recent studies: 6\% of English footballers (32); 30\% of Finnish elite athletes (30); children 3-5\% and 5$15 \%$ for adults, reported by Laure (1997) (33).

\section{CONCLUSION}

The interpretation of the results was based on the components of the theoretical model of risk factors and originated from the attitudes revealed by the questionnaire for athletes (26). These attitudes were analyzed differently according to the categories of athletes and their results. When discussing risk factors for prohibited substance use, the athlete also admitted use or the temptation to use $(14,24)$.

From the cognitive point of view, according to NADA model, $78 \%$ of athletes had been informed about the anti-doping rules and the prohibited list. The information related to prohibited substances and methods is not a factor for doping behavior. Adult and youth athletes with above average tension and depression were tempted to use prohibited substances although they found the information on doping useful (13). From the behavioral point of view of the subjects, athletes, coaches and physicians rejected doping and the opinions of the physician and coach equally influenced the athletes. Regardless of the category and previous results, the athletes, particularly youth, experiencing tensionanxiety or depressive states were tempted to use prohibited substances. Parental influence was clearly and justifiable greater for youth.

PEAS showed good reliability with the developmental sample and the revalidation sample of 73 US college division I football players (Cronbach's alpha $=0.8249$ ), but was weak when used with a general population sample, which provides some evidence for validity (27). Doping intention based on a selfreport questionnaire has inherent limitations relating to social desirability and underreporting (6). Self -report scales may be subject to response bias (34). The prevalence rate for doping was $1.23 \%-12.0 \%$ (NADA) and $1.1 \%$ $15.0 \%$ (PEAS) and fall into the ranges for previous studies $(8,29-33)$.

Impact assessment of social factors motivating the intention to dope relative to the research objectives and existing data confirms the general assumption that doping attitudes and behavior are the result of complex and dynamic internal and external influences. The structure of the personality and social environment constitute risk factors for prevention, placing the athlete between illegality and functionality, ethics and morality. The group or team with which the athlete is affiliated can exercised favorable or unfavorable influences. A lack of moral sense is clearly a risk factor for doping behavior. It appears that more counseling centers and sports clubs are needed to allow athletes to benefit from counseling.

\section{APPLICABLE REMARKS}

- Assessing the impact of social factors motivators of doping intent, report targets research and literature data, confirm the general hypothesis that the attitude and behavior of doping is the result of a complex and dynamic influences internal and external structure of personality and social environment can be risk factors or prevention, placing the athlete between illegality and functionality, ethics and morals.

- Assessing the influence of external factors (social) in the phase of intent, as predictor of rejection or acceptance of the use of dopants agents, may intervene in the decision making process of displacing athletes risk factors in prevention factors. 


\section{ACKNOWLEDGMENTS}

The authors would like to thank Dr. David

Viorel, SC Artego SA, Targu-Jiu, Gorj, Romania and Potzaichin Ivona Beartice, NADA,

Bucharest, Romania.

\section{REFERENCES}

1. Baron DA, Martin DM, Abol Magd S. Doping in sports and its spread to at-risk populations: an international review. World Psychiatry. 2007;6(2):118-23.

2. Pitsch W, Emrich E. The frequency of doping in elite sport: Results of a replication study. International Review for the Sociology of Sport. 2012;47(5):559-80.

3. Barkoukis V, Lazuras L, Tsorbatzoudis H, Rodafinos A. Motivational and sportspersonship profiles of elite athletes in relation to doping behavior. Psychology of Sport and Exercise. 2011;12(3):205-12.

4. Goulet C, Valois P, Buist A, Cote M. Predictors of the use of performance-enhancing substances by young athletes. Clinical journal of sport medicine : official journal of the Canadian Academy of Sport Medicine. 2010;20(4):243-8.

5. Gradidge P, Coopoo Y, Constantinou D. Prevalence of performance-enhancing substance use by Johannesburg male adolescents involved in competitive high school sports. Archives of Exercise in Health and Disease. 2011;2(2):114-9.

6. Lazuras L, Barkoukis V, Rodafinos A, Tzorbatzoudis H. Predictors of Doping Intentions in Elite-Level Athletes: A Social Cognition Approach. Journal of Sport and Exercise Psychology. 2010;32(5):694-710.

7. Pedersen IK. Doping and the perfect body expert: social and cultural indicators of performance-enhancing drug use in Danish gyms. Sport in Society. 2010;13(3):503-16.

8. 2011 Laboratory Testing Figures [Internet]. World Anti-Doping Agency. 2011. Available from: https://wadamain-prod.s3.amazonaws.com/resources/files/WADA-2011-Laboratory-Testing-Figures.pdf.

9. Petróczi A, Mazanov J, Naughton DP. Inside athletes' minds: Preliminary results from a pilot study on mental representation of doping and potential implications for anti-doping. Substance Abuse Treatment, Prevention, and Policy. 2011;6(1):1-8.

10. Ajzen I. The theory of planned behavior. Organizational behavior and human decision processes. 1991;50(2):179-211.

11. Donovan RJ, Egger G, Kapernick V, Mendoza J. A conceptual framework for achieving performance enhancing drug compliance in sport. Sports medicine (Auckland, NZ). 2002;32(4):269-84.

12. Lucidi F, Grano C, Leone L, Lombardo C, Pesce C. Determinants of the intention to use do in substances: An empirical contribution in a sample Italian adolescents. International journal of sport psychology. 2004;35(2):13348.

13. Risk Factors of Doping Behavior related to Personality Structure and Social Environment of the Athletes [Internet]. World Anti-Doping Agency. 2007. Available from: https://www.wada-ama.org/en/resources/socialscience/risk-factors-within-doping-behavior-related-to-personality-structure-and.

14. Vâjiala G, Epuran M, Stanescu M, Potzaichin I, Berbecaru C. Relation between motivation and temptation for using the doping substances in high performance sports. Ovidius University Annals, Series Physical Education and Sport/ SCIENCE, MOVEMENT AND HEALTH. 2010;10(2):207-12.

15. Wiefferink CH, Detmar SB, Coumans B, Vogels T, Paulussen TG. Social psychological determinants of the use of performance-enhancing drugs by gym users. Health education research. 2008;23(1):70-80.

16. Bandura A. Social foundations of thought and action: a social cognitive theory: Prentice-Hall; 1986. 617 p.

17. Fishbein M, Cappella JN. The Role of Theory in Developing Effective Health Communications. Journal of Communication. 2006;56:S1-S17.

18. Lucidi F, Zelli A, Mallia L, Grano C, Russo PM, Violani C. The social-cognitive mechanisms regulating adolescents' use of doping substances. J Sports Sci. 2008;26(5):447-56.

19. Sniehotta F. An Experimental Test of the Theory of Planned Behavior. Applied Psychology: Health and WellBeing. 2009;1(2):257-70.

20.Zelli A, Mallia L, Lucidi F. The contribution of interpersonal appraisals to a social-cognitive analysis of adolescents' doping use. Psychology of Sport and Exercise. 2010;11(4):304-11.

21. Petróczi A, Aidman E. Psychological drivers in doping: The life-cycle model of performance enhancement. Substance Abuse Treatment, Prevention, and Policy. 2008;3:7-.

22. Chan DKC, Hardcastle S, Dimmock JA, Lentillon-Kaestner V, Donovan RJ, Burgin M, et al. Modal salient belief and social cognitive variables of anti-doping behaviors in sport: Examining an extended model of the theory of planned behavior. Psychology of Sport and Exercise. 2015;16, Part 2:164-74. 
23. Nica-Badea D. The study of how information-involvement, preventing and combating the use and abuse of prohibited substances and methods. Târgu-Jiu, România: Constantin Brâncuși University of Târgu Jiu, 2010 Contract No.: 417C/13.10.2009; 9662/09.10.2009, 2-6.

24. Nica-Badea D, Sandor I, Monea G. The research of sportsmen level of information, involvement, motivation involving doping phenomenon. International Congress of Physical Education, Sport and Kinetoterapy; Bucharest, Roumania2011.

25. Yesalis CE, Bahrke MS. Doping among adolescent athletes. Best Practice \& Research Clinical Endocrinology \& Metabolism. 2000;14(1):25-35.

26. Potzaichin I-B. Research on the level of information on the activity of athletes doping Romania. Ştiinţa Sportului. 2007(56):63-70 [Article in Romanian: Abstract in English].

27. The Development and Validation of a Doping Attitudes and Behaviour Scale (DABS) [Internet]. World AntiDoping Agency \& The Irish Sports Council. 2005. Available from: https://www.wadaama.org/en/resources/social-science/the-development-and-validation-of-a-doping-attitudes-and-behaviour-scale.

28. Petroczi A. Attitudes and doping: a structural equation analysis of the relationship between athletes' attitudes, sport orientation and doping behaviour. Subst Abuse Treat Prev Policy. 2007;2:34.

29. Özdemir L, Nur N, Bagcivan I, Bulut O, Sümer H, Tezeren G. Doping and Performance Enhancing Drug Use in Athletes Living in Sivas, Mid-Anatolia: A Brief Report. Journal of Sports Science \& Medicine. 2005;4(3):24852.

30. Alaranta A, Alaranta H, Holmila J, Palmu P, Pietila K, Helenius I. Self-reported attitudes of elite athletes towards doping: differences between type of sport. Int J Sports Med. 2006;27(10):842-6.

31. Laure P, Binsinger C. Doping prevalence among preadolescents athletes. A four-year follow-up. British Journal of Sports Medicine. 2007.

32. Waddington I, Malcolm D, Roderick M, Naik R. Drug use in English professional football. British Journal of Sports Medicine. 2005;39(4):e18.

33. Laure P. Epidemiologic approach of doping in sport. A review. The Journal of sports medicine and physical fitness. 1997;37(3):218-24.

34. Donahue EG, Miquelon P, Valois P, Goulet C, Buist A, Vallerand RJ. A motivational model of performanceenhancing substance use in elite athletes. Journal of sport \& exercise psychology. 2006;28(4):511-20. 